\title{
An exploratory study comparing psychological profiles and its congruence with clinical performance among patients with functional or motility digestive disorders
}

Francisco Jose Eiroa-Orosa ${ }^{1,2}$, Amanda Rodriguez-Urrutia ${ }^{2}$, Anna Accarino ${ }^{2,3}$, Pilar SantamarinaPerez $^{4}$, Gemma Parramon ${ }^{2}$ and Fernando Azpiroz ${ }^{2,3}$

${ }^{1}$ University of East London, UK

${ }^{2}$ Universitat Autònoma de Barcelona, Spain

${ }^{3}$ CIBEREHD, Spain

${ }^{4}$ Hospital Clínic Universitari, Spain

Abbreviated Short Title: Psychological profiles of patients with functional and motility digestive disorders

\begin{abstract}
Functional gastrointestinal disorders (FGDs) have been related with different psychological conditions. On the contrary the role of psychological factors within gastrointestinal motor disorders (GMDs) remains unclear. The objective of this study was to explore the differences and congruence with clinical performance of the psychological profile and subjective functionality among patients diagnosed with FGDs and GMDs. Using a double-blind design, fifty-six inpatients from a Gastroenterology Department were included in the study. No major differences were detected between the two groups. However, clinical performance was coherent with subjective physical functioning only among GMDs. These results may provide useful information for gastroenterologists dealing with patients' complaints not consistent with their clinical profile.
\end{abstract}

Keywords: Functional gastrointestinal disorders, gastrointestinal motility disorders, clinical performance, subjective functionality, congruence. 


\section{INTRODUCTION}

Some patients complain of severe digestive symptoms in the absence of organic causes. Symptoms include abdominal discomfort and/or pain, abdominal distension and inability to consume regular meals. From a gastroenterological point of view, two main diagnostic categories are distinguished: patients in whom a motor dysfunction of the gut can be evidenced by objective criteria (i.e. abnormal motility) classified as gastrointestinal motor disorder (GMDs) and those without objective dysfunction. The clinical manifestations in both categories may be indistinguishable, and the distinction in the most severe cases requires functional tests such as intestinal manometry. Patients without demonstrable GMDs are diagnosed with functional gastrointestinal disorders, (FGDs, Drossman, 2006). Different functional gastrointestinal syndromes have been defined based on clinical criteria. They include irritable bowel syndrome (abdominal pain or discomfort associated with changes in bowel habit), functional dyspepsia (symptoms thought to be originated in the gastroduodenal region in the absence of any organic, systemic, or metabolic disease likely to explain the symptoms) and rumination (persistent or recurrent regurgitation of recently-ingested food into the mouth with subsequent spitting or re-mastication and swallowing, in the absence of structural disease). The causes of functional gastrointestinal disorders are still unknown, hence functional stands actually for idiopathic. Experimental data suggest that FGD symptoms are related to subtle sensory and reflex dysfunctions of the gut that are not detectable by conventional methodologies, leading to reduced tolerance of physiological stimuli in the gut.

Moreover, there is evidence that the development of symptoms is the result of interactions between somatic, psychological, and social factors with high interpersonal variability (Bennett et al., 1998). They are often associated with psychological distress (Koloski, Talley, \& Boyce, 2003), personality characteristics (Fava, Fabbri, Sirri, \& Wise, 2007), child abuse (Lackner et al., 2006), and sociocultural issues mainly related to lifestyles, gender and explanatory models of the disorder among patients and physicians (Chang et al., 2006). Furthermore, epidemiological data points to the presence of psychiatric comorbidities in 40-60\% of patients diagnosed with FGDs (Levy et al., 2006). It has been suggested that people suffering FGDs but not seeking medical advice, have a similar psychological profile to asymptomatic individuals (Drossman et al., 1999). On the contrary, patients with a FGD demanding medical specialised care have more anxiety, depression, health-related anxiety and hypochondriac symptoms; and are less likely to link distress with their symptoms, compared to people not consulting or remaining in primary care (Guthrie et al., 2003; Heaton et al., 1992; Whitehead, Bosmajian, Zonderman, Costa Jr., \& Schuster, 1988). Likewise, some recent studies show similar results in community and primary care settings, suggesting a direct relationship 
between psychological co-morbidity and FGDs, rather than a biased observations in referral centres (Wu, 2012).

While FGDs have been widely studied from a psychological perspective, often showing the presence of diverse symptomatology (Bennett et al., 1998; Drossman et al., 1999; Heaton et al., 1992; Whitehead et al., 1988; $\mathrm{Wu}, 2012)$, GMDs have received less attention from the behavioural sciences. This can be explained as these disorders are evidenced by a structural disease to justify it. However, some studies point out to psychiatric illness causing gastric dysmotility (Peupelmann et al., 2009; Quick et al., 2010; Ruhland et al., 2008). In addition, anxiety and depression levels have been associated with gastroparesis severity and hospitalizations but not with disease aetiology or degree of gastric retention in a wide sample of gastroparesis patients (Hasler et al., 2010).

However, despite all this evidence, the differences between GMDs and FGDs have not still been explored in the context of specialized tertiary care, where the most severe cases are typically treated.. For all these reasons, the aim of this study was to compare the psychological, subjective functionality and clinical assessed performance profiles of patients admitted for specialised assessment in an inpatient tertiary Digestive Unit.

\section{METHODS}

\section{Participants}

During one year, all patients hospitalized for evaluation of gastrointestinal motor function in a highly specialized Digestive Unit based at a tertiary referral centre, were included in this study. Patients had been referred because of suspected gastrointestinal motor abnormality and organic lesions. Mechanical obstruction had been ruled out by a thorough work-up before inclusion in the study. The protocol of the study was approved by the Ethics Committee of the University Hospital Vall d'Hebron and all participants gave their written informed consent.

\section{Clinical assessment}

All patients underwent gastrointestinal and psychiatric evaluation. Among patients not fulfilling criteria of intestinal dysmotility, those with clinical symptoms compatible with gastroparesis, underwent gastric emptying and gastric tone evaluation. Patients without objective evidence of motor disorder (inability, pseudo-obstruction, or gastroparesis) were evaluated using Rome III criteria to establish a FGD diagnosis. 
Regarding psychiatric and psychological assessment, a clinical interview and a battery of psychometric tests were administered in the first 72 hours after hospital admission. All the semistructured interviews were carried out by the same psychiatrist (who was completely blind to patients' digestive diagnosis or any previous clinical information), covering main psychopathological domains according to the SCID I (First, Spitzer, Gibbon, \& Williams, 1997) \& II (First, Gibbon, \& Spitzer, 1997) based on the DSM-IV-TR (American Psychiatric Association, 2000). The selection of questionnaires was done according to the basic psychometric evaluation protocol of the hospital's liaison psychiatry service, including perceived functionality, depression and anxiety, general psychopathology, and personality traits. Additionally, the assessment of alexithymia was introduced, given the findings in studies reporting the increased presence of this trait in patients diagnosed with FGDs (Mazaheri, Afshar, Weinland, Mohammadi, \& Adibi, 2012; Porcelli et al., 2004; Porcelli, De Carne, \& Leandro, 2014). The battery of self-administered questionnaires included:

a) Self-perceived functionality: The Short Form Health Survey, SF-36 (Ware Jr. \& Sherbourne Donald, 1992) was used to measure subjective physical and social functionality.

b) Psychopathology: The Toronto Alexithymia Scale, TAS-20 (Martínez-Sánchez, 1996; Taylor et al., 1988), was used to assess alexithymia, defined as an inability to identify and describe emotions in the self, (Sifneos, 1973), the Hospital Anxiety and Depression Scale, HAD (Zigmond \& Snaith, 1983) to assess anxiety and depression; the Symptom Checklist Revised, SCL-90R (Derogatis, 1994) as a multidimensional measure of general psychopathology (including somatization, obsessivecompulsive, interpersonal sensitivity, depression, anxiety, hostility, phobic anxiety, paranoid ideation and psychoticism domains).

c) Personality traits: The Revised Neuroticism-Extroversion-Openness Five Factor Inventory, NEO-FFI (McCrae \& Costa Jr., 2004) was used for the assessment of personality traits including extraversion, agreeableness, conscientiousness, neuroticism, and openness to experience.

d) Physical assessment: Clinical functional impairment was assessed with the Karnofsky Performance Status (KPS, Karnofsky and Burchenal, 1949). This clinician-administered scale covers a range from 0 (death) to 100 (perfect health). Although it was initially designed to be used with patients diagnosed with cancer, its use has been extended to other medical conditions including digestive disorders (Borgaonkar, 2000). 


\section{Statistical analyses}

Non parametric statistics were used to compare socio-demographic characteristics and psychological measures between groups. Categorical variables were compared between groups using chi-square tests. Continuous variables were compared using Mann-Whitney-Wilcoxon rank-sum test for independent variables with two levels, and Kruskal-Wallis $\mathrm{H}$ for independent variables with 3 levels. Spearman's Rho, a non-parametric statistic, was used to correlate clinical performance with subjective functioning, psychopathology, and personality traits. In the case of multiple comparisons, Bonferroni adjustment was used to correct the alpha level.

\section{RESULTS}

During the study period, fifty-six patients were enrolled in the study (see Figure 1). Four patients were excluded from the study after psychiatric and digestive assessment, as they did not meet criteria for neither FGD nor a GMD (two met criteria for anorexia nervosa, one for a cluster C personality disorder and the last one did not fulfil any psychiatric or digestive diagnosis). Based on gastrointestinal function tests (intestinal manometry and gastric emptying) patients were classified in two subgroups: 17 patients were diagnosed with GMDs (7 inability, 2 gastroparesis and 8 chronic intestinal pseudo-obstruction), and the rest (35 patients in which no objective evidence was found) were diagnosed with FGDs (10 functional dyspepsia, 18 IBS, 7 rumination).

\section{PLEASE INSERT FIGURE 1 AROUND HERE}

\section{Sociodemographic and psychosocial characteristics}

Sociodemographic and psychosocial characteristics are shown in table 1. Patients with objective criteria of gastrointestinal motor dysfunction were younger than those without (i.e. patients diagnosed of functional gastrointestinal disorders), although no statistical significant differences were found. Differences were neither found in the distribution of gender, education, professional activity, marital status or family dynamics.

PLEASE INSERT TABLE 1 AROUND HERE

\section{Psychometric scales}

Psychometric variables are shown in table 2. Patients with motor disorders (GMDs) performed better (higher scores) in SF-36-Physical Role ( $\mathrm{z}=2.186, \mathrm{p}=.029)$, but not in other SF-36 subscales. No statistically significant differences were found in depression (HAD), anxiety (HAD), alexithymia 
(TAS-20), general psychopathology (SCL-90), personality traits (NEO-FFI-R) or clinical severity (KPS).

Regarding sub-diagnoses, no statistically significant differences were found between GMD subgroups (we compared a group of inability or gastroparesis with chronic intestinal pseudoobstruction using Mann-Whitney $U$ ) regarding any psychometric measure. On the contrary, among patients diagnosed of FGDs (we compared functional dyspepsia, IBS and 7 rumination using KruskalWallis $\mathrm{H})$, those with rumination had higher scores in the SF-36 Physical Functioning $(\chi 2=7.474$, $\mathrm{p}=.024)$, NEO-FFI-R Agreeableness $(\chi 2=5.843, \mathrm{p}=.050)$ and Conscientiousness $(\chi 2=6.40, \mathrm{p}=.044)$ scores, compared to patients diagnosed with functional dyspepsia and IBS. No difference remained statistically significant after Bonferroni adjustment $(0.05 / 26=0.002)$.

\section{PLEASE INSERT TABLE 2 AROUND HERE}

\section{Correlation between clinician assessed performance and subjective functionality}

The correlation between clinician (KPS) and patient's assessments of functionality (SF-36 subscales) and the rest of the psychometric measures in both groups, showed statistical significant correlations for SF-36 Physical Functioning ( $\rho=.378, p=.010)$, NEO-FFI Extraversion $(\rho=.313, p=.034)$ and NEOFFI Conscientiousness $(\rho=.323, p=.028)$. Partial correlations controlling for diagnosis showed statistical significant correlations for SF-36 Physical Functioning ( $r=.438, \mathrm{p}=.003)$. When stratifying the analysis, patients with GMDs had statistically significant correlations with SF-36 physical functioning $(\rho=.752, p=.002)$ and SF-36 physical role $(\rho=.540, p=.046)$, while FGDs didn't reach statistical significance for any correlation. For a graphical representation of the correlation of the KPS with SF-36 physical functioning, including 95\% confidence intervals, please see figure 2.

\section{PLEASE INSERT FIGURE 2 AROUND HERE}

\section{DISCUSSION}

Our results show that, among patients with severe symptoms assessed in tertiary care, those diagnosed with FGDs have a similar psychological profile and illness severity to those diagnosed with GMDs. However, despite this similarity, clinician-rated severity was not consistent with the subjective perception of functionality, in the case of patients diagnosed with FGDs. 
This is the first study comparing different psychological and psychopathological variables between GMDs and FGDs in a detailed way. Additionally, psychometric and psychiatric assessment was done blind to digestive diagnosis. Our results focused on the relation between clinician-rated performance, patient-perceived functionality and other psychometric measures including alexithymia, depression, anxiety, general psychopathology, and personality traits. On the one hand, differences between FGDs and GMDs were only found for the SF-36-Physical Role subscale. On the other hand, clinician-rated severity correlated with subjective functionality just in the case of patients diagnosed with GMDs, showing a lack of coherence between clinician-rated severity and perceived functionality for FGDdiagnosed patients.

The scores in psychometric measures, even among patient-rated functionality scores (SF-36), were similar in both groups. This similarity may be explained in the context of a tertiary referral centre, where patients diagnosed with GMDs and FGDs have an equivalent clinician-rated severity. It should be kept in mind that patients diagnosed with FGDs included in this study have a more severe clinical picture that those usually found in the general population or in primary care (Koloski et al., 2003; Okumura, Tanno, Ohhira, \& Tanno, 2010). Although patients with FGDs have been found to have higher levels of neuroticism, distress and anxiety compared with the general population in previous studies, these traits have not been found to differentiate patients consulting with those who do not (Koloski, Talley, \& Boyce, 2002).

Incongruence of self-reported vs. clinician-reported measures of functionality or severity can be seldom found in the medical literature (Cowen, Wakefield, \& Cloutier, 2007; Elser \& Fantl, 1995; Schrader, 1997), but are rarely explored more in depth. To our knowledge, it is the first time this topic is analysed among patients with gastrointestinal pathologies. On the one hand, patients diagnosed with GMD would seem "coherent" with what is expected of them. Patients with more severe clinical pictures, including eating limitations or nasogastric tubes, would have consistent physical functioning problems. On the other hand, some patients diagnosed with FGDs report levels of functionality inconsistent with what clinicians would expect from them. We may approach these results in two ways. Firstly we may appeal to the supposed objectivity of clinical judgment. From this point of view these patients would be perceiving levels of functionality below what they are "really" capable of. However, this may also have to do with a clash of clinician's and patient's expectations. Clinicians' may find clinical complaints to be not consistent with their exploration, while patients might attribute these symptoms to the gastric disease. This leads us to believe that more studies in the future should study in depth factors causing inconsistencies between self- and hetero-reported clinical data. 
Several limitations of the study should also be noted. On one hand, given the low prevalence of GMDs, the sample was too small to deepen in the determinants of the incongruence between subjective and clinician-assessed functionality. On the other hand, these patients have very severe conditions. For this reason, they are derived to a highly specialized unit in a tertiary referral centre. Hence, our data cannot be generalized to primary care patients or the general population.

Despite these limitations, the results of this study may allow the medical community to think about future projects that could further investigate the determinants of the congruence between clinicianreported measures and self-perceived functionality in patients diagnosed with digestive disorders. With respect to this line of research, more studies will be needed to check for different profiles within both diagnostic groups that could explain the inconsistency of subjective with clinician-assessed functionality.

\section{Acknowledgements}

The authors would like to thank all the clinical staff and patients who were involved in this study. This work was supported by the Research Institute of the University Hospital Vall d'Hebron (VHIR), Barcelona, Spain.

\section{Declaration of interest}

The authors report no conflicts of interest regarding the present study. The authors alone are responsible for the content and writing of the paper.

\section{References}

American Psychiatric Association (Ed.). (2000). Diagnostic and statistical manual of mental disorders: DSM-IV-TR. (p. 943). American Psychiatric Publishing.

Bennett, E. J., Piesse, C., Palmer, K., Badcock, C. A., Tennant, C. C., \& Kellow, J. E. (1998). Functional gastrointestinal disorders: psychological, social, and somatic features. Gut, 42(3), 414-420.

Borgaonkar, M. R. (2000). Quality of life measurement in gastrointestinal and liver disorders. Gut, 47(3), 444-454. doi:10.1136/gut.47.3.444

Chang, L., Toner, B. B., Fukudo, S., Guthrie, E., Locke, G. R., Norton, N. J., \& Sperber, A. D. (2006). Gender, age, society, culture, and the patient's perspective in the functional gastrointestinal disorders. Gastroenterology, 130(5), 1435-46. doi:10.1053/j.gastro.2005.09.071 
Cowen, M. K., Wakefield, D. B., \& Cloutier, M. M. (2007). Classifying asthma severity: objective versus subjective measures. The Journal of Asthma: Official Journal of the Association for the Care of Asthma, 44(9), 711-5. doi:10.1080/02770900701595576

Derogatis, L. R. (1994). SCL-90-R: Administration, scoring and procedures manual (3rd edition). (C. P. Research, Ed.). Baltimore.

Drossman, D. A. (2006). Rome III: The Functional Gastrointestinal Disorders. Gastroenterology, 130(5), 1377-1390.

Drossman, D. A., Creed, F. H., Olden, K. W., Svedlund, J., Toner, B. B., \& Whitehead, W. E. (1999). Psychosocial aspects of the functional gastrointestinal disorders. Gut, 45 Suppl 2, II25-30.

Elser, D. M., \& Fantl, J. A. (1995). Comparison of "subjective" and "objective" measures of severity of urinary incontinence in women. Neurourology and Urodynamics, 14(4), 311-316. doi:10.1002/nau.1930140403

Fava, G. A., Fabbri, S., Sirri, L., \& Wise, T. N. (2007). Psychological factors affecting medical condition: a new proposal for DSM-V. Psychosomatics, 48(2), 103-111.

First, M., Gibbon, M., \& Spitzer, R. (1997). Structured Clinical Interview for DSM-IV Axis II Personality Disorders (SCID-II). American Psychiatric Press, Inc. American Psychiatric Press, Inc.

First, M., Spitzer, R., Gibbon, M., \& Williams, J. B. W. (1997). Structured Clinical Interview for DSM-IV Axis I Disorders, Clinician Version (SCID-CV), 132.

Guthrie, E., Creed, F., Fernandes, L., Ratcliffe, J., Van Der Jagt, J., Martin, J., ... Tomenson, B. (2003). Cluster analysis of symptoms and health seeking behaviour differentiates subgroups of patients with severe irritable bowel syndrome. Gut, 52(11), 1616-1622.

Hasler, W. L., Parkman, H. P., Wilson, L. A., Pasricha, P. J., Koch, K. L., Abell, T. L., ... Hamilton, F. (2010). Psychological dysfunction is associated with symptom severity but not disease etiology or degree of gastric retention in patients with gastroparesis. The American Journal of Gastroenterology, 105(11), 2357-67. doi:10.1038/ajg.2010.253

Heaton, K. W., O’Donnell, L. J., Braddon, F. E., Mountford, R. A., Hughes, A. O., \& Cripps, P. J. (1992). Symptoms of irritable bowel syndrome in a British urban community: consulters and nonconsulters. Gastroenterology, 102(6), 1962-1967.

Karnofsky, D., \& Burchenal, J. (1949). The Clinical Evaluation of Chemotherapeutic Agents in Cancer. In C. MacLeod (Ed.), Evaluation of Chemotherapeutic Agents (p. 196). Columbia Univ Press.

Koloski, N. A., Talley, N. J., \& Boyce, P. M. (2002). Epidemiology and health care seeking in the functional GI disorders: a population-based study. The American Journal of Gastroenterology, 97(9), 2290-9.

Koloski, N. A., Talley, N. J., \& Boyce, P. M. (2003). Does psychological distress modulate functional gastrointestinal symptoms and health care seeking? A prospective, community Cohort study. 
The American Journal of Gastroenterology, 98(4), 789-97. doi:10.1111/j.15720241.2003.07388.x

Lackner, J. M., Gudleski, G. D., Zack, M. M., Katz, L. A., Powell, C., Krasner, S., ... Dorscheimer, K. (2006). Measuring health-related quality of life in patients with irritable bowel syndrome: can less be more? Psychosomatic Medicine, 68(2), 312-20. doi:10.1097/01.psy.0000204897.25745.7c

Levy, R. L., Olden, K. W., Naliboff, B. D., Bradley, L. A., Francisconi, C., Drossman, D. A., \& Creed, F. (2006). Psychosocial aspects of the functional gastrointestinal disorders. Gastroenterology, 130(5), 1447-58. doi:10.1053/j.gastro.2005.11.057

Martínez-Sánchez, F. (1996). Adaptación española de la Escala de Alexitimia de Toronto (TAS-20). Clinica Y Salud, 7(1), 19.

Mazaheri, M., Afshar, H., Weinland, S., Mohammadi, N., \& Adibi, P. (2012). Alexithymia and functional gastrointestinal disorders (FGID). Medicinski Arhiv, 66(1), 28-32.

McCrae, R. R., \& Costa Jr., P. T. (2004). A contemplated revision of the NEO Five-Factor Inventory. Personality and Individual Differences, 36(3), 587-596.

Okumura, T., Tanno, S., Ohhira, M., \& Tanno, S. (2010). Prevalence of functional dyspepsia in an outpatient clinic with primary care physicians in Japan. Journal of Gastroenterology, 45(2), 187-94.

Peupelmann, J., Quick, C., Berger, S., Hocke, M., Tancer, M. E., Yeragani, V. K., \& Bär, K.-J. (2009). Lidicate gastric dysmotility in patients sunear and non-linear measures inffering from acute schizophrenia. Progress in Neuro-Psychopharmacology \& Biological Psychiatry, 33(7), 1236 40. doi:10.1016/j.pnpbp.2009.07.007

Porcelli, P., Affatati, V., Bellomo, A., De Carne, M., Todarello, O., \& Taylor, G. J. (2004). Alexithymia and Psychopathology in Patients with Psychiatric and Functional Gastrointestinal Disorders. Psychotherapy and Psychosomatics, 73, 84-91. doi:10.1159/000075539

Porcelli, P., De Carne, M., \& Leandro, G. (2014). Alexithymia and gastrointestinal-specific anxiety in moderate to severe irritable bowel syndrome. Comprehensive Psychiatry, 55(7), 1647-53. doi:10.1016/j.comppsych.2014.05.022

Quick, C., Kliem, A., Berger, S., Hocke, M., Tancer, M., Juckel, G., ... Bär, K.-J. (2010). Gastric dysmotility in major depression. Progress in Neuro-Psychopharmacology \& Biological Psychiatry, 34(1), 92-7. doi:10.1016/j.pnpbp.2009.10.003

Ruhland, C., Koschke, M., Greiner, W., Peupelmann, J., Pietsch, U., Hocke, M., ... Bär, K.-J. (2008). Gastric dysmotility in patients with major depression. Journal of Affective Disorders, 110(1-2), 185-90. doi:10.1016/j.jad.2007.12.236

Schrader, G. D. (1997). Subjective and Objective Assessments of Medical Comorbidity in Chronic Depression. Psychotherapy and Psychosomatics, 66(5), 258-260. doi:10.1159/000289144 
Sifneos, P. E. (1973). The Prevalence of "Alexithymic" Characteristics in Psychosomatic Patients. Psychotherapy and Psychosomatics, 22(2-6), 255-262. doi:10.1159/000286529

Taylor, G. J., Bagby, R. M., Ryan, D. P., Parker, J. D., Doody, K. F., \& Keefe, P. (1988). Criterion validity of the Toronto Alexithymia Scale. Psychosomatic Medicine, 50(5), 500-9.

Ware Jr., J. E., \& Sherbourne Donald, C. (1992). The MOS 36-Item Short-Form Health Survey (SF36): I. Conceptual Framework and Item Selection. Medical Care, 30(6), 473-483.

Whitehead, W. E., Bosmajian, L., Zonderman, A. B., Costa Jr., P. T., \& Schuster, M. M. (1988). Symptoms of psychologic distress associated with irritable bowel syndrome. Comparison of community and medical clinic samples. Gastroenterology, 95(3), 709-714.

Wu, J. C. (2012). Psychological Co-morbidity in Functional Gastrointestinal Disorders: Epidemiology, Mechanisms and Management. Journal of Neurogastroenterology and Motility, 18(1), 13-8. doi:10.5056/jnm.2012.18.1.13

Zigmond, A. S., \& Snaith, R. P. (1983). The hospital anxiety and depression scale. Acta Psychiatrica Scandinavica, 67(6), 361-70. 
Figure 1. Flow diagram of the study.

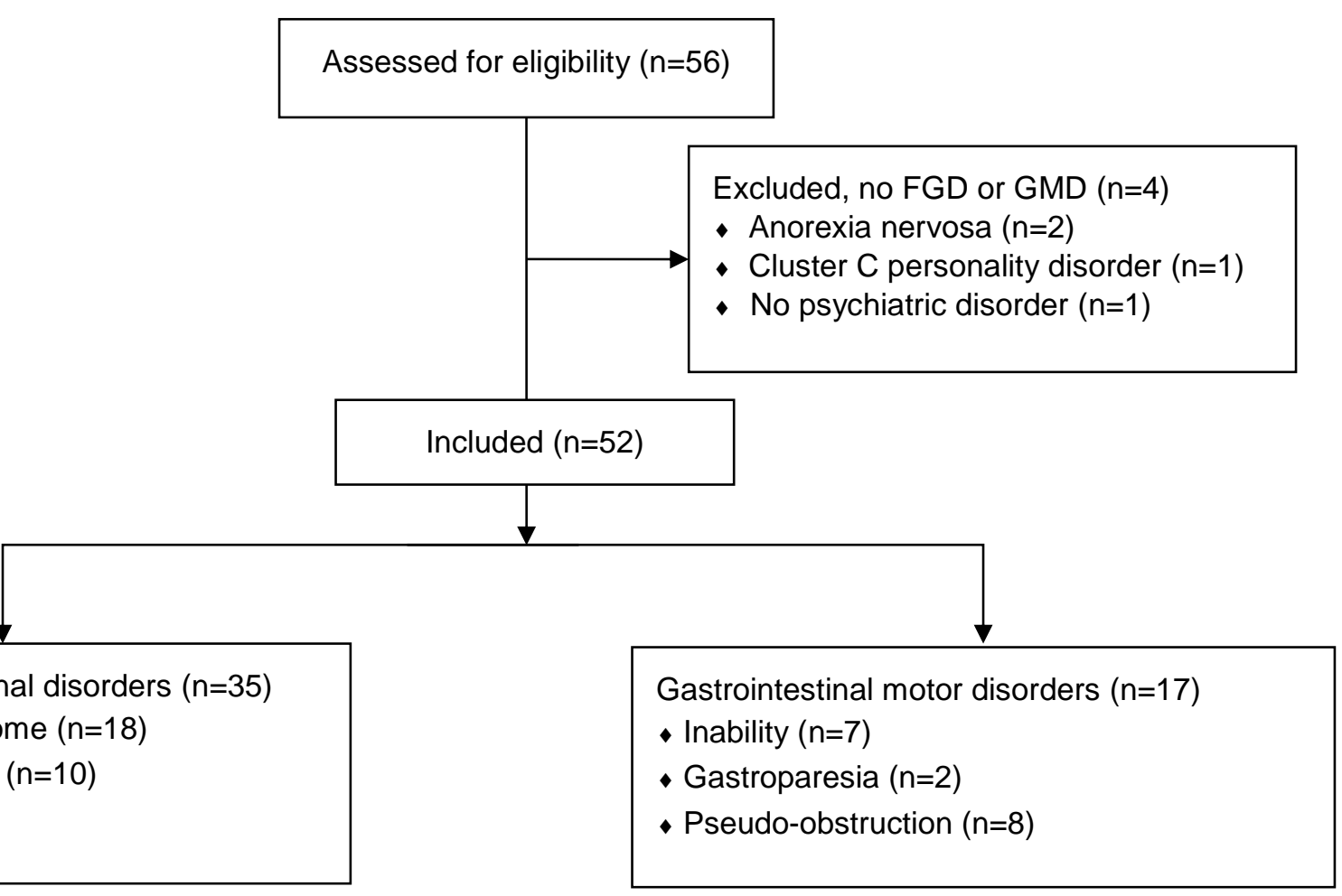


Table 1. Sociodemographic and psychosocial characteristics of the sample

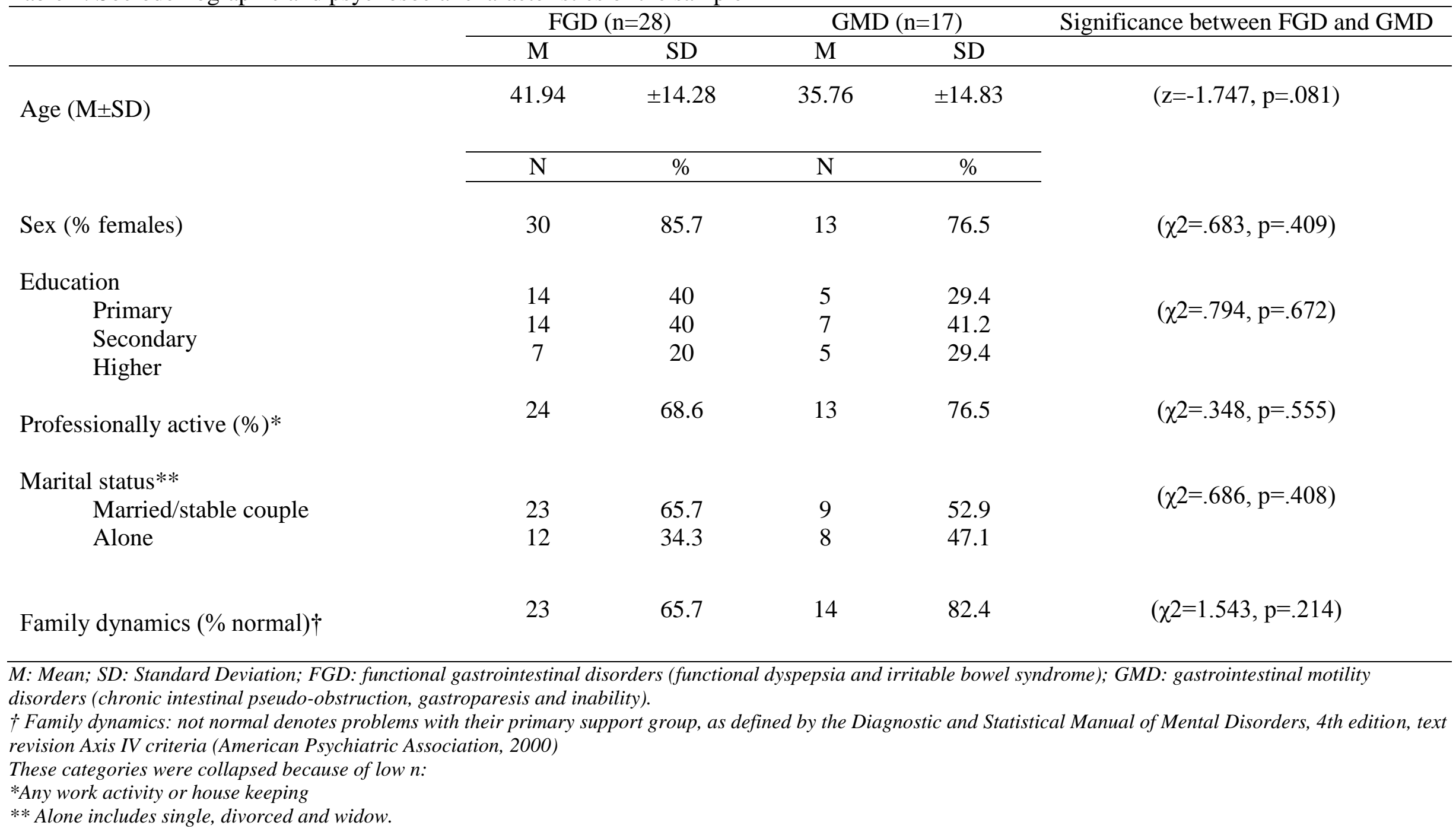


Table 2. Psychometric tests among different diagnosis (means \pm standard deviations).

\begin{tabular}{|c|c|c|c|}
\hline Psychometric test & FGD & GMD & $\begin{array}{c}\text { Significance FGD VS. } \\
\text { GMD }\end{array}$ \\
\hline \multicolumn{4}{|l|}{ SF-36 (T scores) } \\
\hline Physical functioning & $39.68 \pm 12.90$ & $40.79 \pm 14.40$ & $(\mathrm{z}=-.539, \mathrm{p}=.590)$ \\
\hline Physical role & $33.90 \pm 10.52$ & $38.50 \pm 11.93$ & $(\mathrm{z}=-2.186, \mathrm{p}=.029)$ \\
\hline Pain & $34.14 \pm 9.82$ & $36.64 \pm 9.49$ & $(\mathrm{z}=-1.309, \mathrm{p}=.191)$ \\
\hline General health & $36.82 \pm 10.09$ & $35.50 \pm 8.18$ & $(\mathrm{z}=-.659, \mathrm{p}=.510)$ \\
\hline Vitality & $37.64 \pm 10.44$ & $38.36 \pm 10.02$ & $(\mathrm{z}=-.192, \mathrm{p}=.848)$ \\
\hline Social functioning & $29.30 \pm 14.30$ & $33.86 \pm 13.10$ & $(\mathrm{z}=-1.772, \mathrm{p}=.076)$ \\
\hline Emotional role & $43.44 \pm 14.40$ & $42.21 \pm 15.23$ & $(\mathrm{z}=-.529, \mathrm{p}=.597)$ \\
\hline Emotional well-being & $42.22 \pm 11.93$ & $43.57 \pm 12.61$ & $(\mathrm{z}=-.036, \mathrm{p}=.971)$ \\
\hline TAS & $\begin{array}{l}46.16 \pm 13.91 \\
5.18 \pm 4.16\end{array}$ & $\begin{array}{c}48.43 \pm 17.15 \\
5.07 \pm 4.58\end{array}$ & $\begin{array}{l}(\mathrm{z}=-.633, \mathrm{p}=.527) \\
(\mathrm{z}=-.096, \mathrm{p}=.924)\end{array}$ \\
\hline \multicolumn{4}{|l|}{ HAD depression } \\
\hline \multicolumn{4}{|l|}{ HAD anxiety } \\
\hline \multicolumn{4}{|l|}{ SCL90-R (T scores) } \\
\hline Somatization & $62.90 \pm 8.44$ & $61.58 \pm 8.83$ & $(\mathrm{z}=-.527, \mathrm{p}=.598)$ \\
\hline Obsessive- compulsive & $55.61 \pm 13.75$ & $53.42 \pm 15.57$ & $(\mathrm{z}=-.442, \mathrm{p}=.659)$ \\
\hline Interpersonal sensitivity & $52.61 \pm 14.13$ & $52.17 \pm 13.87$ & $(\mathrm{z}=-.016, \mathrm{p}=.987)$ \\
\hline Depression & $59.76 \pm 14.76$ & $58.83 \pm 13.28$ & $(\mathrm{z}=-.278, \mathrm{p}=.781)$ \\
\hline Anxiety & $59.24 \pm 13.73$ & $55.50 \pm 15.35$ & $(\mathrm{z}=-.555, \mathrm{p}=.579)$ \\
\hline Hostility & $51.07 \pm 13.00$ & $53.08 \pm 13.56$ & $(\mathrm{z}=-.696, \mathrm{p}=.486)$ \\
\hline Phobic anxiety & $51.80 \pm 15.72$ & $48.25 \pm 16.02$ & $(\mathrm{z}=-.678, \mathrm{p}=.498)$ \\
\hline Paranoid ideation & $51.02 \pm 15.91$ & $46.83 \pm 13.71$ & $(\mathrm{z}=-.844, \mathrm{p}=.399)$ \\
\hline Psychoticism & $57.78 \pm 13.63$ & $56.17 \pm 15.43$ & $(\mathrm{z}=-.361, \mathrm{p}=.718)$ \\
\hline \multicolumn{4}{|l|}{ NEO-FFI-R (T scores) } \\
\hline Neuroticism & $49.20 \pm 12.73$ & $51.21 \pm 13.47$ & $(\mathrm{z}=-.932, \mathrm{p}=.352)$ \\
\hline Extraversion & $47.71 \pm 9.83$ & $47.86 \pm 9.82$ & $(\mathrm{z}=-.323, \mathrm{p}=.747)$ \\
\hline Openness to Experience & $52.16 \pm 9.85$ & $51.79 \pm 8.71$ & $(\mathrm{z}=-.587, \mathrm{p}=.557)$ \\
\hline Agreeableness & $51.53 \pm 10.42$ & $47.57 \pm 13.10$ & $(\mathrm{z}=-.1 .449, \mathrm{p}=.147)$ \\
\hline Conscientiousness & $54.00 \pm 8.92$ & $52.79 \pm 7.51$ & $(\mathrm{z}=-.743, \mathrm{p}=.458)$ \\
\hline $\begin{array}{l}\text { Karnofsky Performance } \\
\text { Scale }\end{array}$ & $68.43 \pm 16.17$ & $64.12 \pm 20.15$ & $(\mathrm{z}=-0.832, \mathrm{p}=0.405)$ \\
\hline
\end{tabular}


Figure 2. Scatter plots showing the correlation of clinical performance and subjective functionality of patients diagnosed with FGDs (up) and GMDs (down).
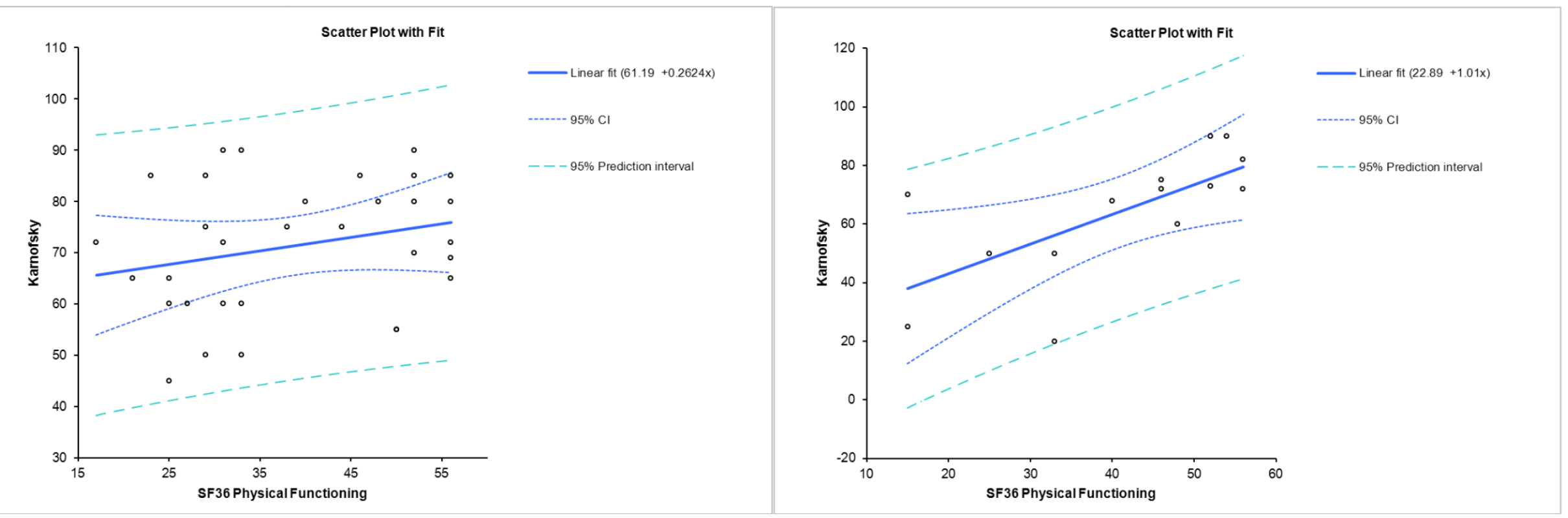